\title{
Source processes of the 2005 West Off Fukuoka Prefecture earthquake and its largest aftershock inferred from strong motion and 1-Hz GPS data
}

\author{
Reiji Kobayashi, Shin'ichi Miyazaki, and Kazuki Koketsu \\ Earthquake Research Institute, University of Tokyo, 1-1-1 Yayoi, Bunkyo-ku, Tokyo 113-0032, Japan \\ (Received August 24, 2005; Revised November 23, 2005; Accepted November 28, 2005; Online published January 27, 2006)
}

\begin{abstract}
We simultaneously inverted strong motion and 1-Hz GPS data recorded during the 2005 west off Fukuoka prefecture earthquake ( $\left.M_{\mathrm{JMA}} 7.0\right)$ for its source process. The data at a GPS station near the source region provided strong constraint on the fault geometry and asperity area. The resultant slip distribution suggests a single asperity close to the Genkai island, where many houses were severely damaged. The maximum slip is $1.4 \mathrm{~m}$, and the total seismic moment is $1.0 \times 10^{19} \mathrm{Nm}\left(M_{\mathrm{W}} 6.6\right)$. We also inverted strong motion data recorded during the largest aftershock $\left(M_{\mathrm{JMA}} 5.8\right)$. The resultant slip distribution shows two asperities on the fault plane. The maximum slip in the major asperity is $0.12 \mathrm{~m}$ and the total seismic moment is $2.0 \times 10^{17} \mathrm{Nm}\left(M_{\mathrm{W}} 5.5\right)$. The main shock and largest aftershock may cause stress change on the Kego fault, which is a major fault running through the city of Fukuoka.
\end{abstract}

Key words: The 2005 west off Fukuoka prefecture earthquake, source process, strong motion, 1-Hz GPS data, joint inversion.

\section{Introduction}

At 10:53 a.m. on March 20, 2005 (JST=UT+9 hours), a shallow earthquake with a magnitude $\left(M_{\mathrm{JMA}}\right)$ of 7.0 , which was estimated by the Japan Meteorological Agency, occurred in the west off Fukuoka prefecture, Japan (Fig. 1). This earthquake killed one person, injured more than one thousand, damaged many houses on the Genkai island close to the source region, and damaged some buildings in the downtown of Fukuoka. The epicenter of the main shock is located in the northwest of the Kego fault which is a major active fault running through the city of Fukuoka.

At 6:11 a.m. on April 20, 2005, the largest aftershock ( $M_{\mathrm{JMA}} 5.8$ ) occurred in the southeast of the main shock. The aftershock distribution immediately before the largest aftershock indicated a seismic gap around the hypocenter of the largest aftershock (Fig. 2). The focal mechanism of the largest aftershock determined by the F-net of the National Research Institute for Earth Science and Disaster Prevention (NIED) (2005) and Ito et al. (2006) showed that the fault strike differs by $8-10^{\circ}$ from that of the main shock. The aftershock distribution after the largest aftershock also shows this difference in the strike. Therefore the fault of the largest aftershock may not be a part of the main source fault, but may be a branch. This fault of the largest aftershock seems to be connected with the Kego fault. It is possible that the main shock and aftershock sequence has changed stress condition on the Kego fault. Source analyses of the main shock and largest aftershock may provide information about the stress change on the Kego fault.

In addition to the strong motion data, we inverted $1-\mathrm{Hz}$

Copyright (c) The Society of Geomagnetism and Earth, Planetary and Space Sciences (SGEPSS); The Seismological Society of Japan; The Volcanological Society of Japan; The Geodetic Society of Japan; The Japanese Society for Planetary Sciences; TERRAPUB.
GPS data recorded during the 2005 west off Fukuoka prefecture earthquake for its source process. Recent studies have demonstrated the ability of 1-Hz GPS data for the studies of source processes in cases of great earthquakes (Larson et al., 2003; Koyama et al., 2004; Irwan et al., 2004; Miyazaki et al., 2004). In this paper we attempted to use $1-\mathrm{Hz}$ GPS data for the source process of a moderate-size earthquake, the west off Fukuoka prefecture earthquake. Ji et al. (2004) have already used 1-Hz GPS data for source process of the 2003 San Simeon earthquake $\left(M_{\mathrm{W}} 6.5\right)$. They used only five $1-\mathrm{Hz}$ GPS stations, which is much less than the number of the seismic stations and may not provide strong constraint on the result. In this study, we use twelve GPS stations, which is equal to the number of the seismic stations, and perform inversions of strong motion data alone, 1-Hz GPS data alone, and the two-fold joint inversion. For the largest aftershock, we inverted strong motion data alone because of low signal-to-noise ratio of the $1-\mathrm{Hz}$ GPS data.

\section{Main Shock}

We used strong motion data recorded by accelerometers at twelve stations of the nation-wide K-NET and KiK-net installed in Japan by the NIED. While the K-NET consists of instruments on the surface only, the KiK-net consists of both borehole instruments (at depths greater than $100 \mathrm{~m}$ ) and surface ones. In general, borehole seismograms are less influenced by the shallow soil conditions than the surface ones. Therefore, we mainly used the KiK-net borehole data and additionally used the K-NET surface data. Figure 1(a) shows the distribution of strong motion stations. In order to obtain filtered velocity seismograms, the seismograms were numerically integrated, bandpass-filtered between 0.05 and $0.5 \mathrm{~Hz}$, resampled at a rate of $2 \mathrm{~Hz}$, and windowed for $30 \mathrm{~s}$ 

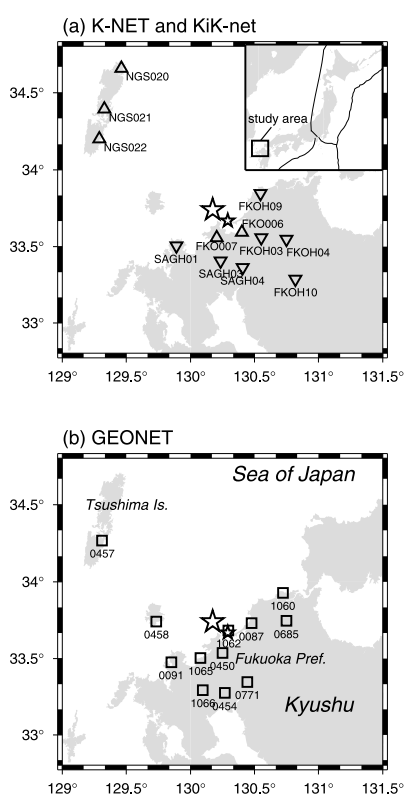

Fig. 1. Station distribution. Large and small stars denote the epicenters of the main shock and largest aftershock, respectively. (a) K-NET (triangle) and KiK-net (inverted triangle) stations. (b) GEONET stations (square).

from $1 \mathrm{~s}$ before the $P$-wave arrivals.

We used GPS data recorded at twelve stations of the GEONET in Japan by the Geographical Survey Institute (GSI) (Fig. 1(b)). The 1-Hz GPS data from the Nippon GPS Data Service corporation were analyzed by using GIPSYOASIS 2 developed at the Jet Propulsion Laboratory (e.g., Zumberge et al., 1997) and rapid products of the International GPS service. The positions of Usuda, Aoshima, and Tonaki are away from the epicenter and they are strongly constrained since the coseismic displacements at these stations assumed to be negligible. The receiver clock at Usuda is used as the reference clock. The resultant GPS displacement waveform data were windowed for the $60 \mathrm{~s}$ including the $S$-waves. We kept the sampling rate of $1 \mathrm{~Hz}$ and the time resolution is therefore worse than that of the strong motion data.

The strong motion and $1-\mathrm{Hz}$ GPS data were inverted for the source process by using the multiple time-window method of Yoshida et al. (1996). Considering the fault geometry, we referred to the aftershock distribution determined by the JMA. Since station 1062 of the GEONET is close to the fault, the static displacement there is very sensitive to the fault geometry (Nishimura et al., 2006). Thus we carried out some preliminary inversions assuming various fault geometries, and we finally adopted a fault with the geometry of $($ strike, dip, slip $)=\left(123^{\circ}, 87.7^{\circ},-1^{\circ}\right)$, which recovered the static displacement at the station 1062 well. The rupture is assumed to be initiated at the hypocenter determined by the Kyushu University (latitude $33.75^{\circ} \mathrm{N}$, longitude $130.16^{\circ} \mathrm{E}$, depth $14.0 \mathrm{~km}$ ). The $32 \times 28 \mathrm{~km}^{2}$ fault plane was assumed and was divided into fifty-six $4 \times 4 \mathrm{~km}^{2}$ subfaults. We let the slip angle change from $-46^{\circ}$ to $44^{\circ}$.

The Green's functions for strong motions were calculated by using the reflectivity method, which was originally developed by Kohketsu (1985) and modified by Hikima and
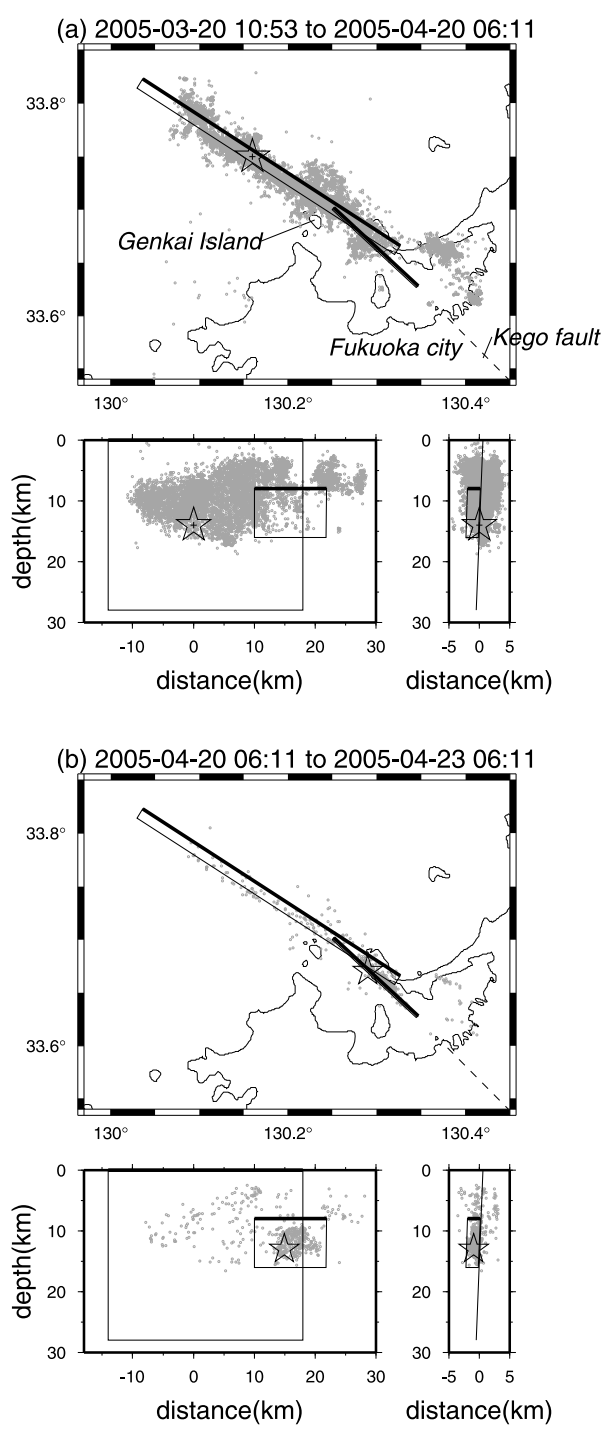

Fig. 2. Fault geometries for the main shock and the largest aftershock. Gray circles are hypocenters of the aftershocks (a) between the main shock and largest aftershock and (b) in three days after the largest aftershock occurred. Large and small stars denote hypocenters of the main shock and the largest aftershock, respectively. Fault geometries are represented by boxes (thick lines are the top edges). Bottom left and right panels show vertical cross-section parallel to and perpendicular to the strike direction of the main shock fault, respectively.

Koketsu (2004) and Koketsu et al. (2004) for buried receivers. The Green's functions for 1-Hz GPS data were calculated by using the frequency-wavenumber (FK) method developed by Zhu and Rivera (2002). The Green's functions by the FK method can reproduce both dynamic and static displacement components. In the method of Yoshida et al. (1996), each subfault is approximated by a point dislocation source placed at its center. However, this approximation is too rude for the station 1062 and nearby subfaults. We then distributed $8 \times 8$ virtual sources on each of the subfaults and averaged their waveforms for the central point source.

The 1-D structures for the calculation of Green's functions were constructed based on Kawase et al. (2003). We modified them using the genetic algorithm coded by the first author, which is based on Goldberg (1989) and Kobayashi and Nakanishi (1994), so as to find a 1-D structure mini- 
(a) Slip distribution

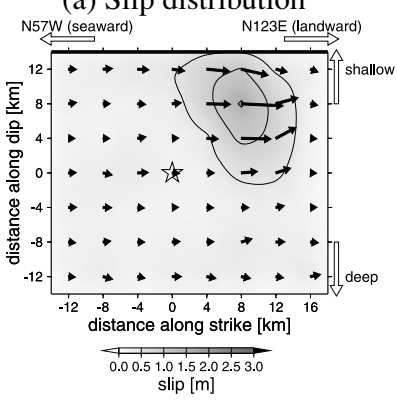

(c) Strong motions

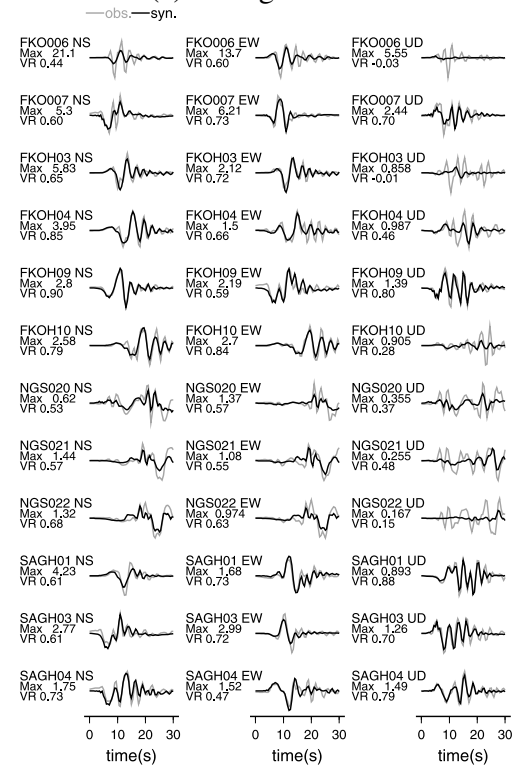

Fig. 3. Result from an inversion of the strong motion alone for the main shock. (a) Slip distribution. Star denotes the hypocenter. The contour interval is $0.5 \mathrm{~m}$. (b) Slip rate functions in the subfaults. Small crosses denote the locations of the point sources in the subfaults. (c) Observed (gray) and calculated (black) strong motions. Station name, component, maximum amplitude (Max) in $\mathrm{cm} / \mathrm{s}$, and variance reduction (VR) are given to the left of each waveform. The variance reduction for all the waveforms is 0.59 .

mizing differences between synthetic and observed seismograms of some large aftershocks excluding the largest.

The source time function is assumed to be six ramp functions with a rise time of $1.0 \mathrm{~s}$. We carried out the preliminary inversions with rupture velocities, which trigger time of the first time window at each subfaults, between 2.0 and $3.4 \mathrm{~km} / \mathrm{s}$, and chose a velocity that minimizes the difference between the observed and synthetic seismograms. We applied the positivity and smoothing constrains during the inversion (Yoshida et al., 1996). The weight for the smoothing constraint were determined to minimize the Akaike's Bayesian information criterion (Akaike, 1980).

We first inverted strong motion data alone for the main shock assuming the rupture velocity of $3.0 \mathrm{~km} / \mathrm{s}$. For the NS and EW components at FKO006 and NS component at FKO007 near the fault, we chose 2.1, 1.4, and 1.2 times heavier weights than those for the others, respectively. Figure 3 shows the resultant slip distribution and compares the observed and calculated strong motions. This solution indicates an asperity (an area of large slips) on shallow, southeastern part of the fault plane. The maximum slip is $1.6 \mathrm{~m}$, (a) Slip distribution

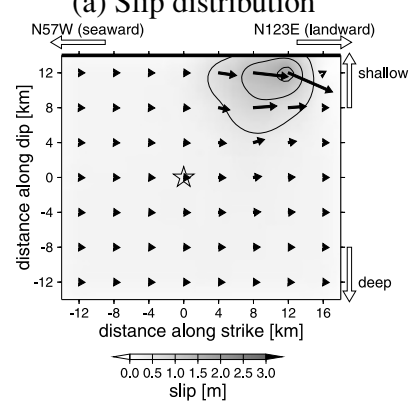

(b) Slip rate function

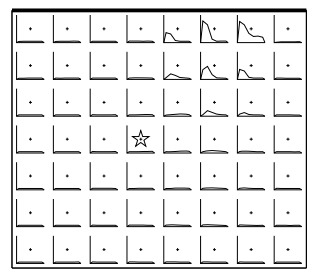

(c) 1-Hz GPS data

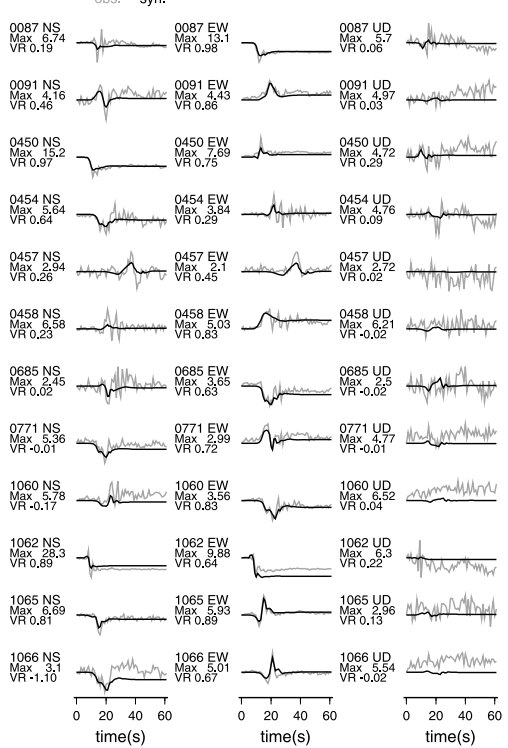

Fig. 4. Result from an inversion of the 1-Hz GPS data alone for the main shock. (a) Slip distribution. (b) Slip rate functions in the subfaults. (c) Observed (gray) and calculated (black) 1-Hz GPS data. Station name, component, maximum amplitude in $\mathrm{cm}$, and variance reduction are given to the left of each waveform. The variance reduction for all the waveforms is 0.35 .

and the total seismic moment is $1.2 \times 10^{19} \mathrm{Nm}\left(M_{\mathrm{W}} 6.7\right)$. Although most the seismograms were well recovered (the variance reduction is 0.59 ), the synthetic vertical components at FKO006, FKOH03, FKOH10, and NGS022 were not in good agreement with the observed ones. These stations are close to the $P$-wave radiation node of the strike slip fault. Therefore the vertical components are small and very sensitive to the details of the fault geometry and threedimensional structure along the paths. These may be reasons for the disagreement.

We next inverted 1-Hz GPS data alone. We assumed the rupture velocity of $2.7 \mathrm{~km} / \mathrm{s}$. The NS component at the station 1062 was weighted 2.8 times more heavily than the others. Figure 4 shows the resultant slip distribution and compares the observed and calculated $1-\mathrm{Hz}$ GPS waveforms. The slip distribution indicates one asperity in the shallow, southeastern part of the fault plane, quite similar to that inferred from the previous inversion of strong motions. However, the asperity is confined to the shallowest subfaults and the maximum slip of $1.8 \mathrm{~m}$ is larger than that of the previous inversion. This concentration is required by the static displacement of about $18 \mathrm{~cm}$ at the GPS station of 1062 . The total seismic moment of $9.1 \times 10^{18} \mathrm{Nm}\left(M_{\mathrm{W}} 6.6\right)$ is 
(a) Slip distribution

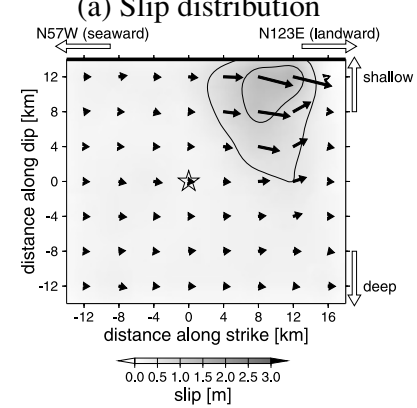

(c) Strong motions

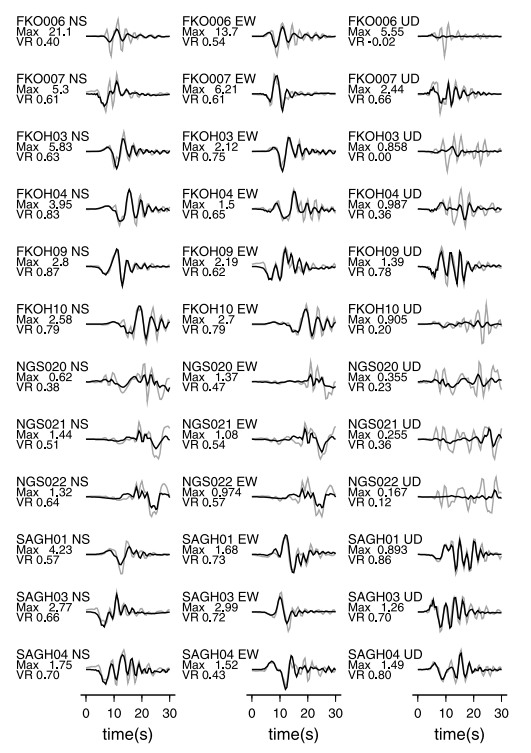

(b) Slip rate function

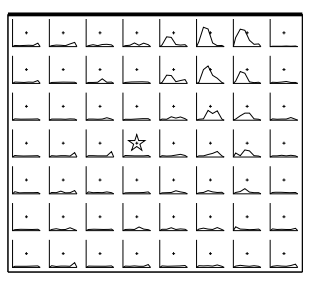

(d) $1-\mathrm{Hz}$ GPS data

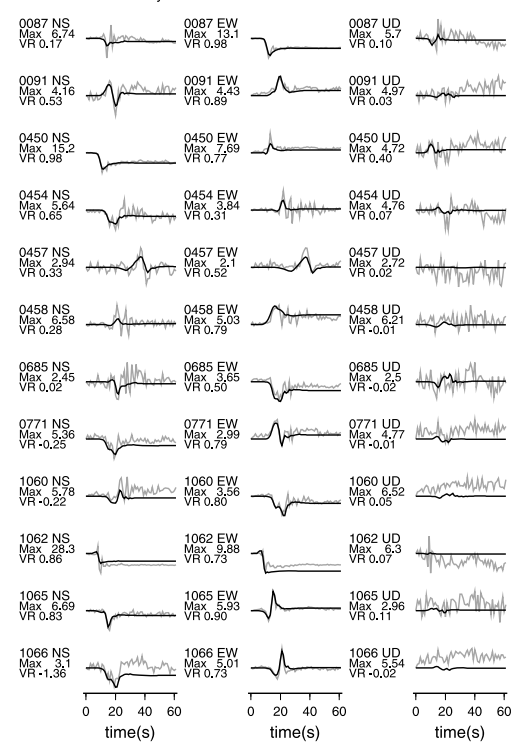

Fig. 5. Result from a joint inversion of the strong motion and 1-Hz GPS data for the main shock. (a) Slip distribution. (b) Slip rate functions in the subfaults. (c) Observed (gray) and calculated (black) strong motions. The variance reduction for all the strong motions is 0.56 . (d) Observed (gray) and calculated (black) $1-\mathrm{Hz}$ GPS data. The variance reduction for all the $1-\mathrm{Hz}$ GPS waveforms is 0.34 .

slightly smaller than the previous inversion. The synthetic waveforms of the horizontal components are mostly in good agreement with the observed ones (the variance reduction for the horizontal components is 0.49), but those of the vertical components are worse (the variance reduction is 0.07 ) because of the low signal-to-noise ratio.

We simultaneously inverted the strong motion and $1-\mathrm{Hz}$ GPS data all together. We assumed the rupture velocity of $3.0 \mathrm{~km} / \mathrm{s}$. All the waveforms were equally weighted except for the components mentioned above. Figure 5 shows the resultant slip distribution and compares the observed and calculated waveforms. The maximum slip is $1.4 \mathrm{~m}$, and the total seismic moment is $1.0 \times 10^{19} \mathrm{Nm}\left(M_{\mathrm{W}} 6.6\right)$. The peak is located the shallower subfaults as shown in the result from the GPS data inversion, but the synthetic strong motions are still in good agreement with the observed ones (the change of variance reduction from 0.59 to 0.56 was small). Therefore, the 1-Hz GPS data provided strong constraint on the asperity.

\section{Largest Aftershock}

We finally inverted the strong motion alone for the source process of the largest aftershock of April 20. We used strong motion data recorded at the same stations as those used for the main shock. The observed seismograms were processed similarly to those of the main shock except for the sampling rate of $5 \mathrm{~Hz}$.

For the fault geometry, we adopted a focal mechanism of $($ strike, dip, slip $)=\left(133^{\circ}, 88^{\circ},-33^{\circ}\right)$ determined by the JMA and the hypocenter determined by the Kyushu University (latitude $33.67^{\circ} \mathrm{N}$, longitude $130.29^{\circ} \mathrm{E}$, depth 13.0 $\mathrm{km})$. The $12 \times 8 \mathrm{~km}^{2}$ fault plane was assumed and was divided into twenty-four $2 \times 2 \mathrm{~km}^{2}$ subfaults. We let the slip angle change from $-78^{\circ}$ to $12^{\circ}$. The source time function is assumed to be four ramp functions with a rise time of $0.5 \mathrm{~s}$. Preliminary analysis gives the rupture velocity of $3.2 \mathrm{~km} / \mathrm{s}$ that minimizes the difference between the observed and synthetic seismograms.

Figure 6 shows the resultant slip distribution and comparison between observed and synthetic seismograms. The solution shows two asperities, the major one on the shallow, southeastern part of the fault plane, and the minor one on the shallow, northwestern part. The maximum slip in the major asperity is $0.12 \mathrm{~m}$ and the total seismic moment is $2.0 \times 10^{17} \mathrm{Nm}\left(M_{\mathrm{W}} 5.5\right)$. The slip vectors show lateral strike slip.

\section{Discussion}

The present study successfully inverted $1-\mathrm{Hz}$ GPS data for the source process of the main shock with a moderate 
(a) Slip distribution

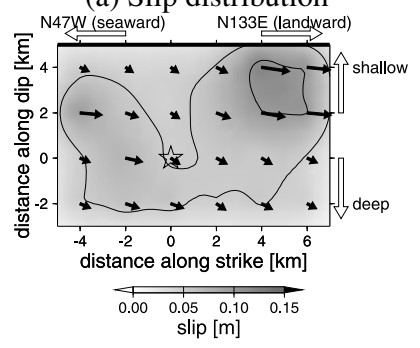

(b) Slip rate function

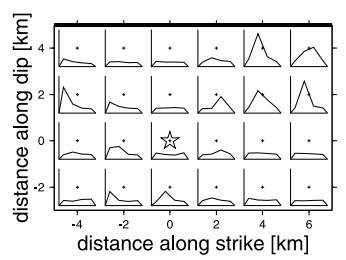

(c) Strong motions

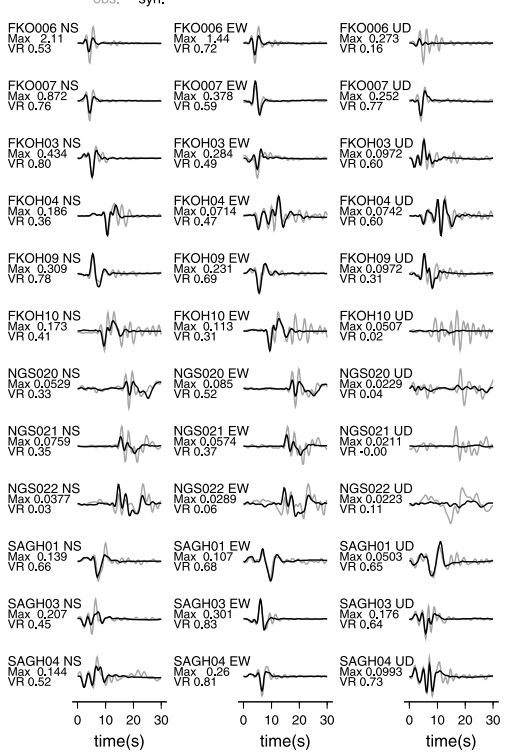

Fig. 6. Result from an inversion of the strong motion alone for the largest aftershock. (a) Slip distribution. Star denotes the hypocenter. The contour interval is $0.05 \mathrm{~m}$. (b) Slip rate functions in the subfaults. (c) Observed (gray) and calculated (black) strong motions. The variance reduction for all the waveforms is 0.48 .

magnitude ( $M_{\mathrm{JMA}} 7.0$ and $M_{\mathrm{W}} 6.6-6.7$ ). The slip distribution is consistent with that from the inversion of strong motion data, and the horizontal components of 1-Hz GPS waveform are well recovered. The station 1062 of the GEONET is closest to the source region, and its data provided strong constraint on the fault geometry and asperity area. Figure 7 shows the result from an inversion of the 1$\mathrm{Hz}$ GPS alone without the data of 1062 . The peak moved to the northwest. The maximum slip significantly decreased from $1.8 \mathrm{~m}$ to $0.85 \mathrm{~m}$, and the total seismic moment slightly decreased from $9.1 \times 10^{18} \mathrm{Nm}\left(M_{\mathrm{W}} 6.6\right)$ to $8.8 \times 10^{18} \mathrm{Nm}$ $\left(M_{\mathrm{W}} 6.6\right)$. The slip distribution is rather similar to that from the inversion of strong motion data alone.

The resultant slip distribution shows that the asperity area of the main shock is located shallower than the hypocenter and is not adjacent to the hypocenter. This feature was also shown in the slip distribution of the 2000 western Tottori earthquake ( $M_{\text {JMA }}$ 7.3) (Iwata and Sekiguchi, 2002; Semmane et al., 2005), but many large earthquakes show that the hypocenter was located in or adjacent to the asperity. In addition, the aftershock distribution of the 2005 west off Fukuoka prefecture earthquake is also similar to that of the 2000 western Tottori earthquake. Most of the aftershocks of both earthquakes occurred at depths between the hypocenter and asperity (Fig. 8). Semmane et al. (2005) suggested (a) Slip distribution

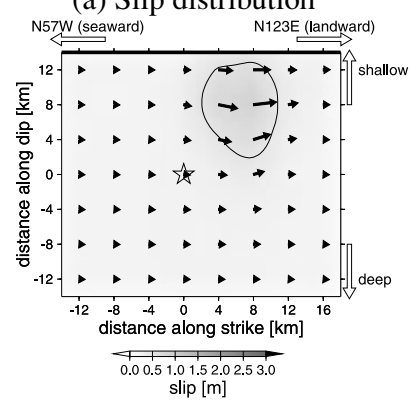

(b) Slip rate function

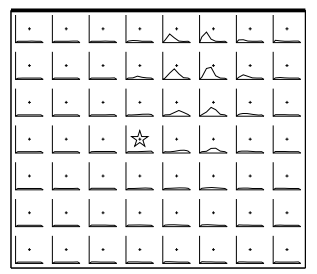

(c) 1-Hz GPS data

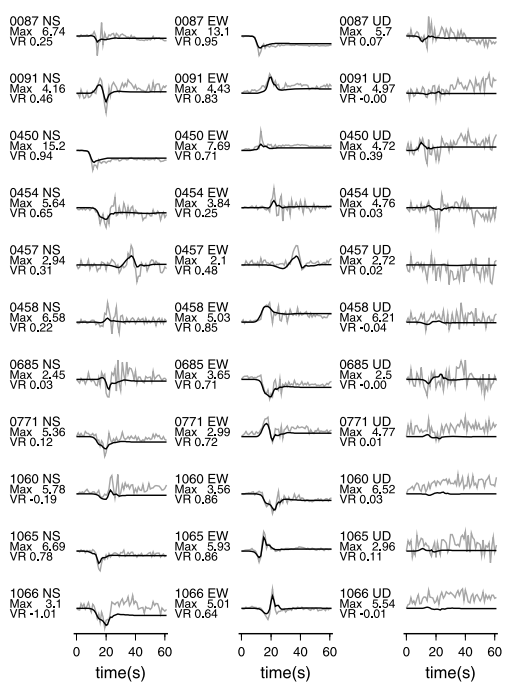

Fig. 7. Slip distribution from an inversion of the 1-Hz GPS data alone without the data of the station 1062. The variance reduction for all the waveforms is 0.33 .

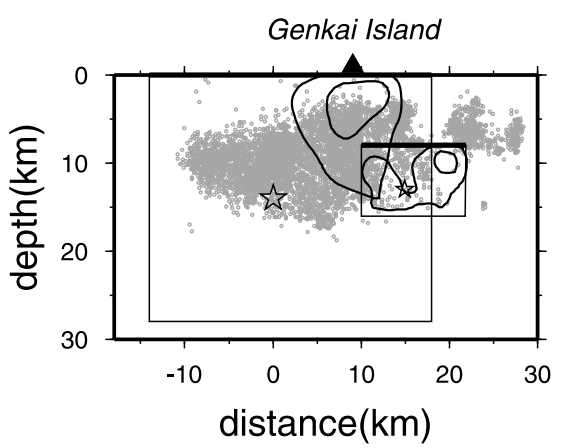

Fig. 8. Contour map of slip distributions of the main shock and largest aftershock. The contour intervals are $0.5 \mathrm{~m}$ for the main shock and $0.05 \mathrm{~m}$ for the largest aftershock. Large and small stars denote hypocenters of the main shock and largest aftershock, respectively. Circles are aftershocks between the main shock and largest aftershock. Triangle denotes the Genkai island.

that the source region of the 2000 western Tottori earthquake is classified into four layers, the bottom layer where the failure began, the second layer where many aftershocks occurred, the third layer where coseismic slip is maximum, and the top layer where neither slip (the 2000 western Tottori earthquake occurred on subsurface fault) nor aftershock occurred. This classification may be applicable to the 2005 west off Fukuoka prefecture earthquake.

The asperity region is close to the Genkai island, where 
many houses were damaged. Although the distance between the hypocenter and the Genkai island is about $17 \mathrm{~km}$, the distance between the top of the asperity and the Genkai island is $2-3 \mathrm{~km}$. This closeness to the asperity may be directly linked to the severe damage. The damaged buildings in Fukuoka city were mostly distributed in the northeastern side of the Kego fault. Sato and Kawase (2006) showed that the thick Quaternary sediments $(\sim 50 \mathrm{~m})$ above the preTertiary bedrock mainly contributed the damage.

The largest aftershock occurred in a gap of the aftershock distribution. We infer that the seismic gap may be associated with the difference between the fault strikes of the main shock and the largest aftershock. The rupture propagation of the main shock may have ended around the seismic gap as shown by the slip distribution (Fig. 8), and the stress on the branch fault of the largest aftershock increased. Then the largest aftershock released the stress on the branch fault, but may have increased stresses around the tip of the branch fault, in particular in the southeast of the asperity shown in Fig. 6, where the aftershock activity is low.

\section{Conclusion}

We inverted strong motion and 1-Hz GPS data for source processes of the main shock and largest aftershock of the 2005 west off Fukuoka prefecture earthquake. The inversion of the 1-Hz GPS data alone for the main shock $\left(M_{\mathrm{JMA}}\right.$ 7.0) successfully recovered the slip distribution, which is consistent with that from the strong motion data alone. We combined the 1-Hz GPS data with the strong motion and inverted them. Compared with the result from strong motion alone, the asperity has been concentrated. This concentration is mainly caused by the displacement at a GPS station closest to the source region. The maximum slip is $1.4 \mathrm{~m}$, and the total seismic moment is $1.0 \times 10^{19} \mathrm{Nm}\left(M_{\mathrm{W}} 6.6\right)$. The resultant slip distribution suggests that an asperity is close to the Genkai island, where many houses were damaged.

The largest aftershock occurred on a fault that branches off the fault of the main shock. The resultant slip distribution shows two asperities on the fault. The maximum slip in the major asperity is $0.12 \mathrm{~m}$ and the total seismic moment is $2.0 \times 10^{17} \mathrm{Nm}\left(M_{\mathrm{W}} 5.5\right)$. The main shock and aftershock sequence may change stress field around the Kego fault.

Acknowledgments. Strong motion data are provided by the KNET and KiK-net of National Research Institute for Earth Science and Disaster Prevention (NIED), and 1-Hz GPS data are recorded by the GEONET of the Geographical Survey Institute. We used hypocentral location data determined by the Japan Meteorological Agency (JMA) and Kyushu University, and focal mechanisms from the F-net of the NIED and the JMA. We thank L. Zhu and R. Graves for providing us with their FK code. We also thank to two anonymous referees and K. Yomogida for valuable comments which improved the manuscript. All the figures were drawn by using the Generic Mapping Tools (Wessel and Smith, 1991). This work is supported by Grant-in-Aid for Scientific Research (No. 17800001) and the Special Project for Earthquake Disaster Mitigation in Urban Areas (DaiDaiToku project) from the Ministry of Education, Culture, Sports, Science and Technology of Japan.

\section{References}

Akaike, H., Likelihood and Bayes procedure, in Bayesian Statistics, edited by J. M. Bernardo et al., pp. 143-166, Univ. Press, Valencia, Spain, 1980.

Goldberg, D. E., Genetic Algorithms in Search, Optimization, and Machine Learning, 412 pp, Addison-Wesley, 1989.

Hikima, K. and K. Koketsu, Source process of the foreshock, mainshock and largest aftershock in the 2003 Miyagi-ken Hokubu, Japan, earthquake sequence, Earth Planets Space, 56, 87-93, 2004.

Irwan, M., F. Kimata, K. Hirahara, T. Sagiya, and A. Yamagiwa, Measuring ground deformations with 1-Hz GPS data: the 2003 Tokachioki earthquake (preliminary report), Earth Planets Space, 56, 389-393, 2004.

Ito, Y, K. Obara, T. Takeda, K. Shiomi, T. Matsumoto, S. Sekiguchi, and S. Hori, Initial-rupture fault, main-shock fault, and aftershock faults: Fault geometry and bends inferred from centroid moment tensor inversion of the 2005 west off Fukuoka prefecture earthquake, Earth Planets Space, 58, this issue, 69-74, 2006.

Iwata, T. and H. Sekiguchi, Source process of the 2000 western Tottori earthquake and strong ground motions in the epicentral area, Earth Monthly, 38, 182-188, 2002 (in Japanese).

Ji, C., K. M. Larson, Y. Tan, K. W. Hudnut, and K. Choi, Slip history of the 2003 San Simeon earthquake constrained by combining 1-Hz GPS, strong motion, and teleseismic data, Geophys. Res. Lett., 31, L17608, doi:10.1029/2004GL020448, 2004.

Kawase, H., K. Nagato, and S. Nakamichi, Damage prediction of Fukuoka city for a scenario earthquake based on strong ground motions evaluated by a hybrid technique, J. Struct. Eng., 49B, 7-16, 2003 (in Japanese with English abstract).

Kobayashi, R. and I. Nakanishi, Application of genetic algorithms to focal mechanism determination, Geophys. Res. Lett., 21, 729-732, 1994.

Kohketsu, K., The extended reflectivity method for synthetic near-field seismograms, J. Phys. Earth, 33, 121-131, 1985.

Koketsu, K., K. Hikima, S. Miyazaki, and S. Ide, Joint inversion of strong motion and geodetic data for the source process of the 2003 Tokachioki, Hokkaido, earthquake, Earth Planets Space, 56, 329-334, 2004.

Koyama, J., N. V. Shestakov, and R. Honda, Strong ground motion recorded by high-rate sampling GPS at the closest site to the 2003 Tokachi-oki earthquake, Earth Planets Space, 56, 383-387, 2004.

Larson, K. M., P. Bodin, and J. Gomberg, Using 1-Hz GPS data to measure deformations caused by the Denali fault earthquake, Science, $\mathbf{3 0 0}$, 1421-1424, 2003.

Miyazaki, S., K. M. Larson, K. Choi, K. Hikima, K. Koketsu, P. Bodin, J. Haase, G. Emore, and A. Yamagiwa, Modeling the rupture process of the 2003 September 25 Tokachi-Oki (Hokkaido) earthquake using 1-Hz GPS data, Geophys. Res. Lett., 31, L21603, doi:10.1029/2004GL02145, 2004.

National Research Institute for Earth Science and Disaster Prevention, Spatial distribution of F-net moment tensor solutions for the 2005 West Off Fukuoka earthquake, Report of the coordinating committee for earthquake prediction, 74, 477-478, 2005.

Nishimura, T., S. Fujiwara, M. Murakami, H. Suito, M. Tobita, and H Yarai, Fault model of the 2005 Fukuoka-ken Seiho-oki earthquake estimated from coseismic deformation observed by GPS and InSAR, Earth Planets Space, 58, this issue, 51-56, 2006.

Satoh, T. and H. Kawase, Simulation of strong motions in Fukuoka City during the 2005 West Off Fukuoka Prefecture Earthquake with special reference to thick Quaternary sediments around the Kego fault, Earth Planets Space, 58, this issue, 105-110, 2006.

Semmane, F., F. Cotton, and M. Campillo, The 2000 Tottori earthquake: A shallow earthquake with no surface rupture and slip properties controlled by depth, J. Geophys. Res., 110, B03306, doi:10.1029/2004JB003194, 2005.

Wessel, P. and W. H. F. Smith, Free software helps map and display data, EOS Trans. Am. Geophys. Union, 72, 441-446, 1991.

Yoshida, S., K. Koketsu, B. Shibazaki, T. Sagiya, T. Kato, and Y. Yoshida, Joint inversion of near- and far-field waveforms and geodetic data for the rupture process of the 1995 Kobe earthquake, J. Phys. Earth, 44, 437-454, 1996.

Zhu, L. and L. A. Rivera, A note on the dynamic and static displacements from a point source in multilayered media, Geophys. J. Int., 148, 619627, 2002.

Zumberge, J. F., M. B. Heflin, D. C. Jefferson, M. M. Watkins, and F. H. Webb, Precise point positioning for the efficient and robust analysis of GPS data from large networks, J. Geophys. Res., 102, 5005-5017, 1997. 